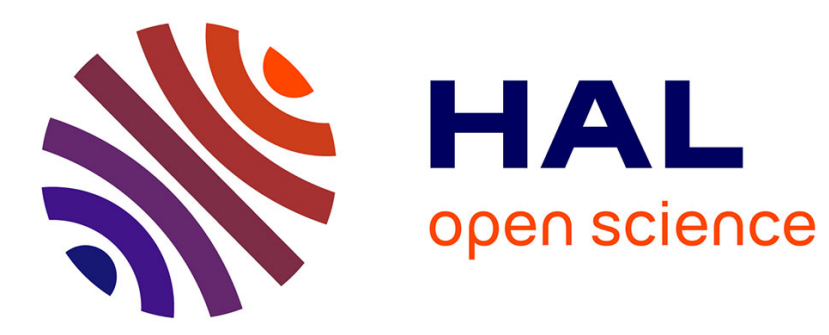

\title{
Characterization of electromagnetic fields of radiating systems by thermo-fluorescence
}

Hugo Ragazzo, Daniel Prost, Jean-François Bobo, Stéphane Faure

\section{To cite this version:}

Hugo Ragazzo, Daniel Prost, Jean-François Bobo, Stéphane Faure. Characterization of electromagnetic fields of radiating systems by thermo-fluorescence. 2020 International Symposium on Electromagnetic Compatibility - EMC EUROPE, Sep 2020, Rome, Italy. pp.1-6, 10.1109/EMCEUROPE48519.2020.9245854 . hal-03016862

\section{HAL Id: hal-03016862 https://hal.science/hal-03016862}

Submitted on 20 Nov 2020

HAL is a multi-disciplinary open access archive for the deposit and dissemination of scientific research documents, whether they are published or not. The documents may come from teaching and research institutions in France or abroad, or from public or private research centers.
L'archive ouverte pluridisciplinaire HAL, est destinée au dépôt et à la diffusion de documents scientifiques de niveau recherche, publiés ou non, émanant des établissements d'enseignement et de recherche français ou étrangers, des laboratoires publics ou privés. 


\section{Characterization of electromagnetic fields of radiating systems by thermo-fluorescence}

\author{
Hugo Ragazzo \\ ONERA/DEMR \\ Université de Toulouse \\ F-31055 Toulouse, France \\ hugo.ragazzo@onera.fr
Stephane Faure
$\angle P C N O$ \\ INSA \\ F-31055 Toulouse, France \\ s-faure@insa-toulouse.fr
}

\author{
Daniel Prost \\ ONERA/DEMR \\ Université de Toulouse \\ F-31055 Toulouse, France \\ daniel.prost@onera.fr
}

\author{
Jean-François Bobo \\ CNRS \\ CEMES \\ F-31055 Toulouse, France \\ jfbobo@cemes.fr
}

\begin{abstract}
Characterization of the electromagnetic field emitted by various sources (antenna, radar) is an important issue, either for civil or defense applications. The measurement of the electromagnetic field may be performed by a local probe, the infrared thermography imaging being an alternative way. The latter method, called EMIR [1] (ElectroMagnetic InfraRed) has been used for years at ONERA where it had been developed. We have recently successfully implemented this technique in the domain of visible light, named as EMVI [2] (ElectroMagnetic Visible Imaging). As in EMIR, a thin film (sensitive to either electric field or magnetic field) is heated by the emitted field. But here the film is coated with a polymer doped with fluorescent molecules. As the fluorescent emission depends on the temperature of the film, we achieve a novel thermofluorescent sensor. The results presented here illustrate that new method: both magnetic and electric field imaging of two different radiating systems
\end{abstract}

Keywords-Electromagnetism, Thermography, Magnetic losses, Electric losses, Thermo-fluorescence, Meta-material, Zero Order Antenna, High Impedance Surfaces

\section{Introduction}

We present in this paper a method for electromagnetic field measurement and imaging in visible wavelengths using fluorophore. In a first step we detail the general principles of this method, then we present measurements of electric and magnetic near field of radiating systems.

In electromagnetic compatibility an issue is the measurement of the electromagnetic field, in particular the near field cartography, to study its interaction with the environment. Strong expansion of the microwave technologies in our environment can be observed for global civil applications (GPS, communications, phone...) or more specific technologies (remote sensing, aeronautics, medicine ...). Interaction between the microwaves and the surrounding environment thus requires a fast method for imaging and measuring the electromagnetic field.

There are different strategies to characterize the electromagnetic field on a large scale. One is to use electromagnetic probes $[3,4]$ in matrix or with a scanning system. The main disadvantages are the long acquisition time, the intrusive behavior and the large size of the scanning system. Another approach, introduced by Hasegawa [5] in 1995 , is to use sensitive films.
We choose an alternative way using thermo-sensitive films which had been developed for infrared thermography method called EMIR (ElectroMagnetic InfraRed). Our objective in the present work is to replace IR thermography by thermo-fluorescence spectroscopy; thus we move to visible range, to improve the spatial resolution of the images.

The film is an electric or magnetic absorbent coated with a thermo-fluorescent layer. In the presence of an electromagnetic field, the energy absorbed by the film is converted into heat, leading to a variation of the fluorescence intensity. The variation of the fluorescence intensity (AFluo) is recorded and post-processed to obtain the incident field. Low frequency modulation of the RF signal, coupled to synchronous demodulation of fluorescence signal, permits to cancel the conduction and convection phenomena that would degrade the field visualization.

\section{GENERAL PRINCIPLES}

\section{A. Experimental Set-Up}

Figure 1 is the schematics of the EMVI setup [6]. The microwave power is modulated at $0.2 \mathrm{~Hz}$. The film is exposed to green LED spot (wavelength: $535 \mathrm{~nm}$ ). The fluorescence variation is registered by an S-CMOS camera (Dhyana400D 4 Megapixel). The S-CMOS camera is equipped with a low-pass $580 \mathrm{~nm}$ filter in order to collect the fluorescence signal.

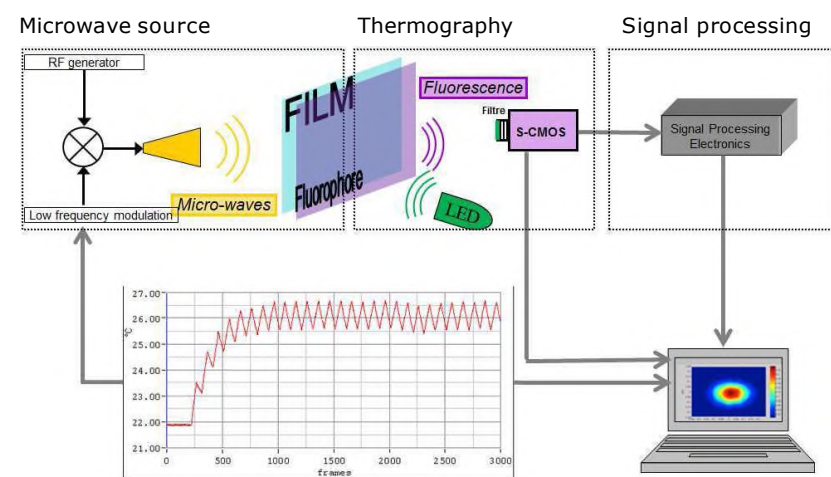

Figure 1 Thermo-fluorescence imaging setup schematics 


\section{B. Thermo-sensitive thin films}

We use two kinds of thermo-sensitive films, one sensitive to the electric field and the other sensitive to the magnetic field.

To measure the electric field $E$, we use a thin film with low-conductivity: $\sigma=10$ to $100 \mathrm{~S} / \mathrm{m}$.The film, a Kapton ${ }^{\circ}$ type doped with carbon, has a surface impedance:

$$
Z_{s}=\frac{1}{\sigma e}=2 \mathrm{k} \Omega
$$

Where $\sigma\left(\mathrm{S} . \mathrm{m}^{-1}\right)$ the electric conductivity and $e(\mu \mathrm{m})$ the thickness of the film (e=50 $\mu \mathrm{m}$ for the Kapton film). The coupling between the electric field and the sensitive thin film generates heat via Joule losses. Under microwave excitation, the Kapton film absorption rate $A$ is related to the surface impedance $Z_{s}$ [7]:

$$
A=\frac{4 Z_{s} Z_{0}}{\left(z_{0}+2 z_{s}\right)^{2}}
$$

In our case the absorption rate $\mathrm{A}$ is about $15 \%$, which is large enough to generate a heat variation that is measurable, and weak enough to keep it not intrusive. The density of absorbed power $P_{a b s}$ (in W.m ${ }^{-3}$ ) is related to the electric field by:

$$
\mathrm{P}_{\mathrm{abs}}=\frac{2 \mathrm{z}_{\mathrm{s}}}{\mathrm{e}\left(\mathrm{Z}_{0}+2 \mathrm{Z}_{\mathrm{s}}\right)^{2}} \mathrm{E}^{2}
$$

$\mathbf{P}_{\mathrm{abs}}$ is proportional to the square of the amplitude of the electric field. As the heating is proportional to $P_{a b s}$, we have:

$$
|\mathrm{E}|=\mathrm{k}_{\mathrm{E}} \sqrt{\Delta \mathrm{T}_{\mathrm{avg}}}
$$

With $k_{E}$ a constant of proportionality.

To measure the magnetic field $\mathrm{H}$, we use a thin film composed of ferromagnetic micro-particles embedded in polymer matrix. These films are manufactured by TOKIN $^{\circledR}$ japanese Company [8] for shielding applications. They are electrically insulating and have a good magnetic susceptibility. Depending on the excitation frequency of the magnetic field, two main losses processes can be invoked: at low frequency (typically dc-1 MHz range), hysteresis losses will be responsible for heating with an effective absorption defined by the SAR (specific absorption rate):

$$
S A R=A . f
$$

With A the area of the magnetization hysteresis loop $(\mathrm{J} / \mathrm{g})$ and $f$ the excitation frequency [9]. Note that $A$ is proportional to the square of the magnetic field amplitude in the low magnetic field regime.

At larger excitation frequency $(0.1$ to $10 \mathrm{GHz})$, in the microwave regime, Ferromagnetic Resonance (FMR) losses or precessional losses will take over hysteresis losses. They are related to the imaginary part of the permeability of the ferromagnetic material and the field frequency. Thus the absorbed power $\mathrm{P}_{\mathrm{abs}}\left(\mathrm{W} \cdot \mathrm{m}^{-3}\right)$ is proportional to the square of the magnetic field $\mathrm{H}$ :

$$
P_{a b s}=\pi f \mu^{\prime \prime} H^{2}
$$

With realistic values of $\mu$ " (10 to 100 ), e (film thickness: 30 to $300 \mu \mathrm{m}), \sim 1 \mathrm{GHz}$ frequency, we end up with a surface absorbed power (e.P $\mathrm{P}_{\mathrm{abs}}$ ) of several percent of the excitation power $\left(\mu_{0} \mathrm{H}^{2} / 2\right)$, therefore compatible with low intrusiveness of the sensing film.

In summary, the magnetic field amplitude is proportional to the square root of the observed temperature change:

$$
|H|=k_{H} \sqrt{\Delta T_{a v g}}
$$

With $k_{H}$ a constant of proportionality.

\section{Thermo-fluorescent Layer}

The fluorescence layers are made of Rhodamine B diluted in ethanol and embedded in epoxy resin. Those layers must fulfill the following characteristics: (i) absorption and emission wavelengths have to be discriminated; this is the case for $\mathrm{RhB}$ where the emission wavelength is $580 \mathrm{~nm}$ and the absorption wavelength is $555 \mathrm{~nm}$. (ii) The fluorescence must depend on temperature; for $\mathrm{RhB}$ we have a variation of the quantum yield proportional to the temperature variation, with fluorophore sensitivity of $2 \% / \mathrm{K}$ (and this variation is linear from 273 to $393 \mathrm{~K}$ [10]). (iii) The thickness of the layer must remain below the thermal diffusion length $\mathrm{D}$. We assume that we are in the case of thin film that simplifies the heat equation in 2D:

$$
\mathrm{t}<\mathrm{D}\left(\mathrm{f}_{\bmod }\right)
$$

With $t$ the thickness of the film (including the fluorescent coating) and $\mathrm{D}\left(f_{\text {mod }}\right)$ the thermal diffusion length, which depends on the modulation frequency $f_{\text {mod }}$. In our case $\mathrm{D}\left(f_{\text {mod }}\right)=50$ to $500 \mu \mathrm{m}$, for $f_{\text {mod }}=1$ to $0.1 \mathrm{~Hz}$, and $\mathrm{t}=80 \mu \mathrm{m}$ (Kapton $+\mathrm{RhB}$ ) or $\mathrm{t}=60 \mu \mathrm{m}$ (Tokin $+\mathrm{RhB})$.

\section{Lock-in thermography}

We use a lock-in thermography technique $[11,12]$ to increase the signal to noise ratio of the measurement. This technique permits to avoid continuous thermal effects like natural convection. The microwave power is modulated and the evolution of the temperature can be written as (See Figure 2):

$\mathrm{T}(\mathrm{t})=\mathrm{T}_{\text {env }}+\Delta \mathrm{T}_{\text {avgmod }}\left(1-\mathrm{e}^{-\left(\frac{\mathrm{t}}{\tau}\right)}\right)+\frac{\Delta \mathrm{T}_{\text {mod }}}{2} \Pi\left(\mathrm{f}_{\text {mod }}, \varphi\right)(9)$

With $\Delta \mathrm{T}_{\bmod }$ and $\Theta$ the peak to peak amplitude and phase angle of a square function $\Pi\left(f_{\text {mod }}\right)$ of a duty cycle $f_{\text {mod. }}$. 


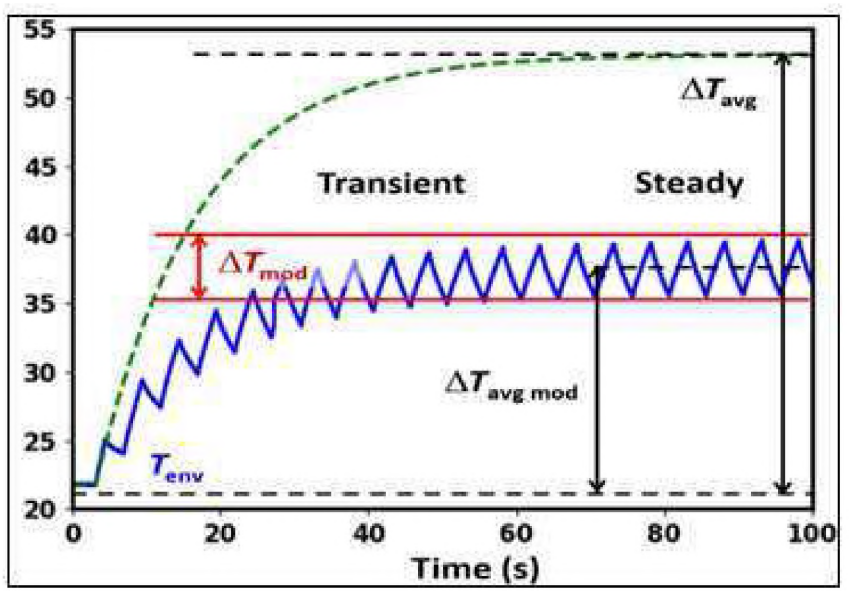

Figure 2 TOKIN-film heating evolution under constant (dotted green line) and $0.2 \mathrm{~Hz}$ modulated (blue line) magnetic excitation [6]

We want to extract $\Delta \mathrm{T}_{\text {mod. }}$ A good approximation is

$$
\Delta T_{\text {mod }}=\frac{P_{a b s} e}{\sqrt{4 h^{2}+\left(\rho C_{p} e \omega\right)^{2}}}
$$

With $\mathrm{P}_{\mathrm{abs}}, \mathrm{h}$ the heat transfer coefficient $\left(10 \mathrm{~W} \cdot \mathrm{m}^{-2} \cdot \mathrm{K}^{-1}\right.$ for natural convection), $\rho$ the conductivity and $C_{p}$ the heat capacity.

The modulated signal of fluorescence is proportional to the heat. For example, Figure 3 shows the evolution of the signal of one pixel of the camera. Applying a fast Fourier transform algorithm, we obtain the mean $\Delta$ Fluo on each pixel and therefore the $\Delta \mathrm{T}_{\bmod }$ [13]. Then, $\mathrm{E}$ or $\mathrm{H}$ amplitude can be deduced from (4) and (7) respectively.

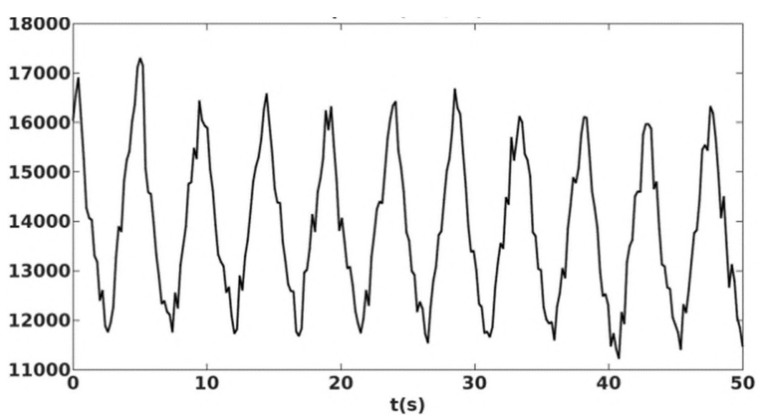

Figure 3 Evolution of fluorescence under $0.2 \mathrm{~Hz}$ modulated magnetic excitation

\section{ZERO ORDER ANTENNA (ZOR)}

\section{A. Introduction}

A zero order antenna is made of capacitor and inductor elements which are swapped on the transmission line (See Figure 4) [14]. Microstrips were etched onto a $0.762 \mathrm{~mm}$ thick $\mathrm{Cu}$-clad Arlon substrate, with a relative permittivity of 2.55. The spatial period was $2.5 \mathrm{~mm}$, and the line width was about $1.5 \mathrm{~mm}$. We chose interdigitated capacitors to get the series lumped elements, made of eight $100 \mu \mathrm{m}$-separated strips, with a surface of about $1.5 \mathrm{~mm} \times 2 \mathrm{~mm}$. The shunt inductances were $100 \mu \mathrm{m}$ wide and $13.5 \mathrm{~mm}$ long meander lines. They were connected to $2 \mathrm{~mm} \times 4.8 \mathrm{~mm}$ ground capacitors, in order to avoid vias. It is difficult to make measurements on such system because of its small size.

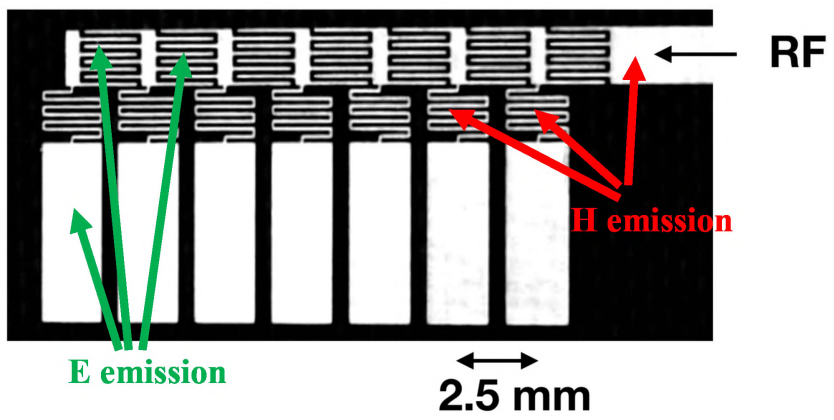

Figure 4 Zero order antenna schematics

\section{B. Images of electric and magnetic field of ZOR antenna}

Images of the electric and magnetic near fields emitted by the ZOR antenna have been achieved. For the measurements, the sensitive films were placed at $2 \mathrm{~mm}$ and the microwave frequency was $4.29 \mathrm{GHz}$.

In Figure 5 we present an image of the electric field $(\mathrm{V} / \mathrm{m})$ with $\mathrm{k}_{\mathrm{E}}=603$ (4). The microwave power is $37 \mathrm{dBm}$ (around $8 \mathrm{~W}$ ). Figure 5 (b) reveals a main emission lobe and Figure 5 (c) secondary lobes. On secondary lobes we can observe the spatial period of the periodic elements of the ZOR. The electric emission is due to the capacitor elements (see Figure 4). In Figure 5 we can observe that the electric field patterns are localized on the capacitor elements.

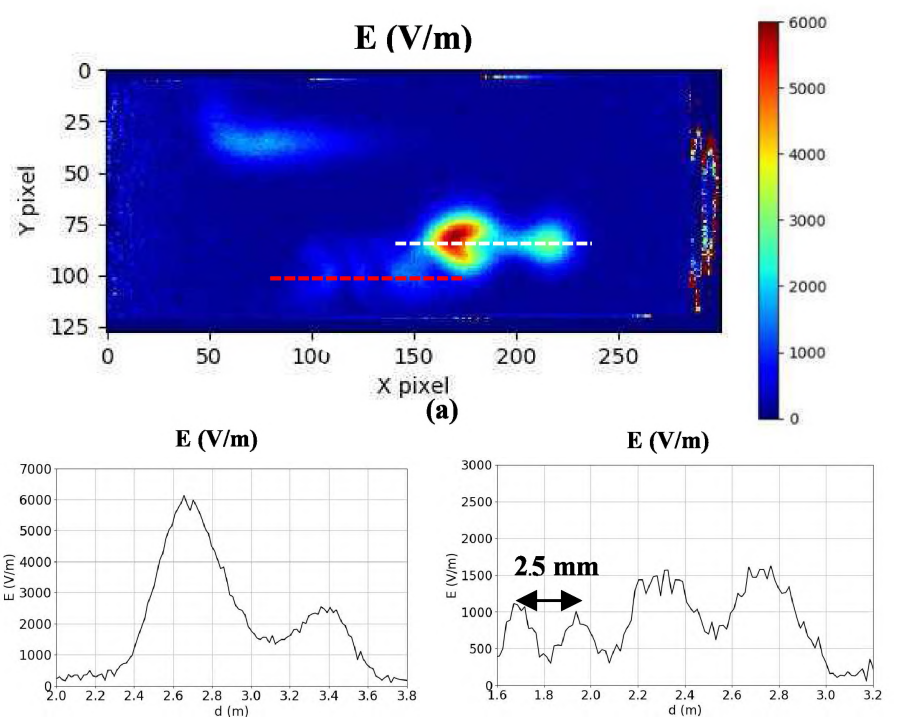

Figure 5 (a) Image of electric field of ZOR antenna at $4.29 \mathrm{GHz}$, (b) profile of the (thin lobe (white dotted), (c) profile of the secondary lobes (red dotted)

Figure 6 represents the square root of $\Delta \mathrm{T}_{\text {mod, }}$ therefore proportional to the magnetic field (7). We thus obtain magnetic field image and profile. The microwave power is $38 \mathrm{dBm}$ (around $6 \mathrm{~W}$ ). Figure 6 also reveals a main emission lobe and secondary lobes. On the secondary lobes we observe the spatial period of the periodic capacitor and inductor elements. As the magnetic emission is due to the 
inductor elements, we can observe in Figure 6 the magnetic near field pattern localized on those elements.

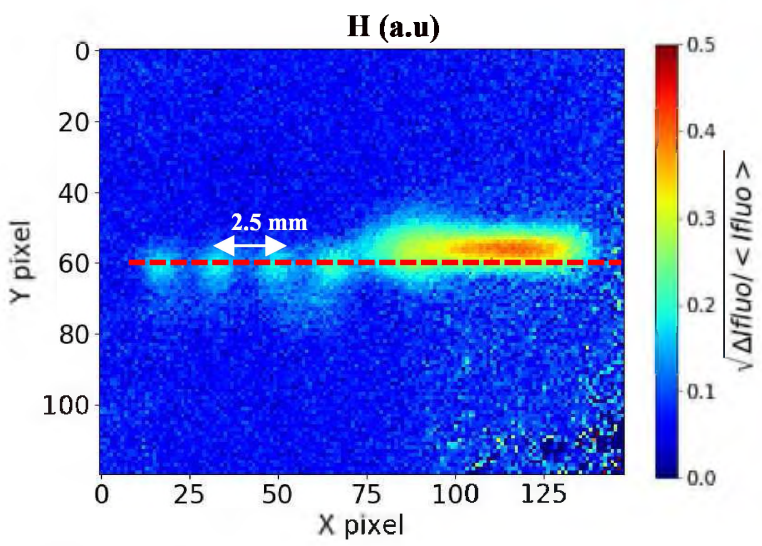

(a)

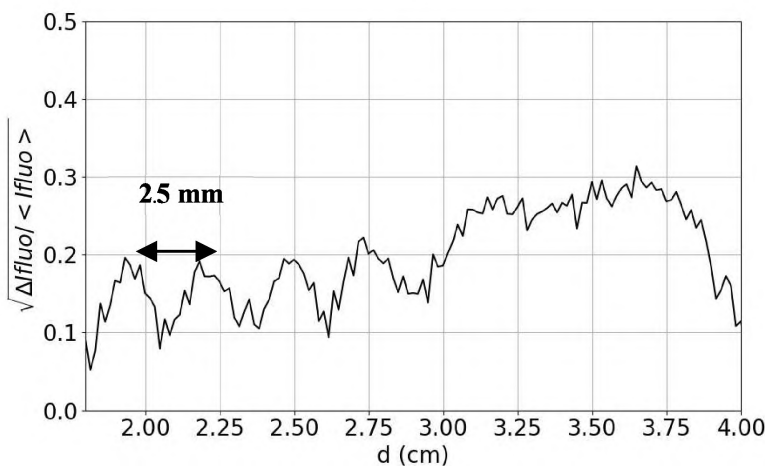

Figure 6 (a) Demodulated image of the magnetic field of ZOR antenna at 4.29 GHz, (b) Profile (red dotted)

\section{HIGH IMPEDANCE SURFACE (HIS)}

\section{A. Introduction}

HIS is a special passive electromagnetic structure (based on metamaterial technology) designed for reducing mutual coupling between patches antennas (for applications where size constraints are crucial: space systems for example).

(a)
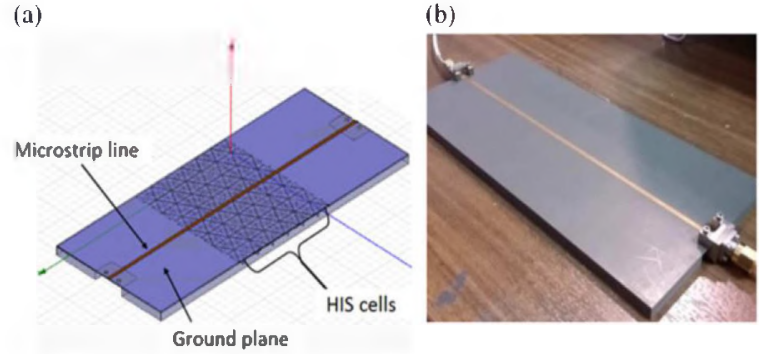

Figure 7 Simulation setup of the HIS embedded in the transmission line and picture of the realized structure [15]

Figure 7 shows how the HIS cells are located between the ground plane and the transmission line [16]. It is made of periodic elements consisting of two layers dielectric substrate. The first dielectric layer includes a ground plane on the bottom face. The second layer is made of the same material as the first. This layer is printed on its two faces with copper. On the bottom face there are hexagon shape pattern and on the top face, equilateral triangle shape pattern with metallic via to connect the ground plane. The HIS is therefore composed of periodic capacitive and inductive elements. We can simply model HIS by a LC parallel circuit.

\section{B. Images of electric field of HIS}

We present in this section images of electric and magnetic field of HIS for a range of frequencies from $1 \mathrm{GHz}$ to $1.8 \mathrm{GHz}$. Figure 8 shows the experimental setup for this measurement.

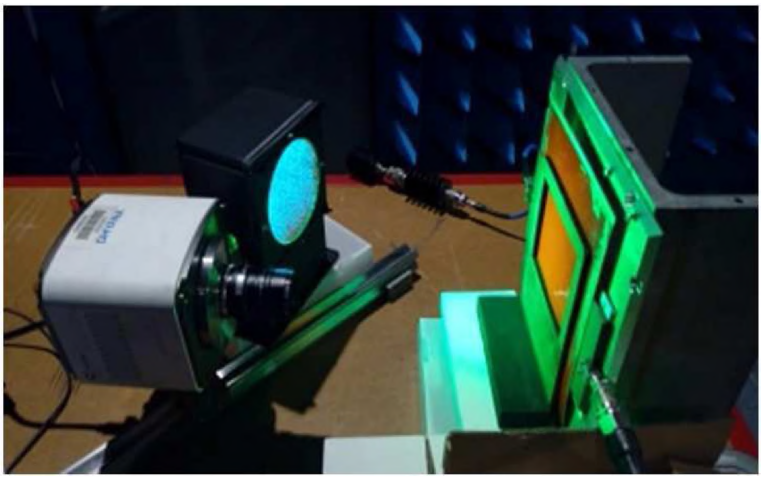

Figure 8 Experimental setup for the measurement of the magnetic field of the HIS

Figure 9 presents the measured $S_{12}$ parameter with and without the film [15]. It can be observed that the band gap frequencies are conserved with the presence of the sensitivefilm. So we can conclude that the film is non-intrusive. We can observe two cut-off frequencies at $1.3 \mathrm{GHz}$ and $1.9 \mathrm{GHz}$ (EMVI measurements will therefore be achieved for the first cut-off frequencies).

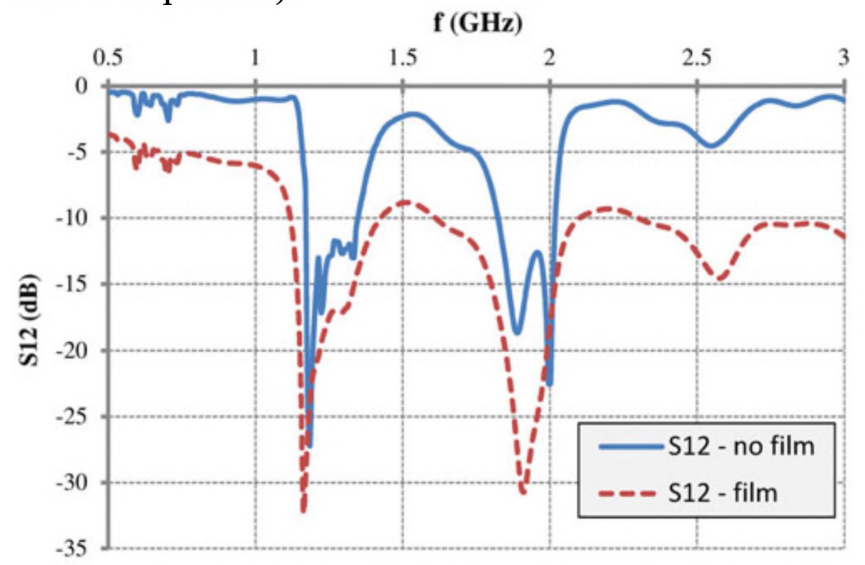

Figure $9 S_{12}$ measurement of the HIS, with and without the thermo-emissive film [15]

Figure 10 shows the amplitude of the field $(\mathrm{V} / \mathrm{m})$ on the HIS line, for different frequencies (from 1 to $1.8 \mathrm{GHzFigure}$ 10): 


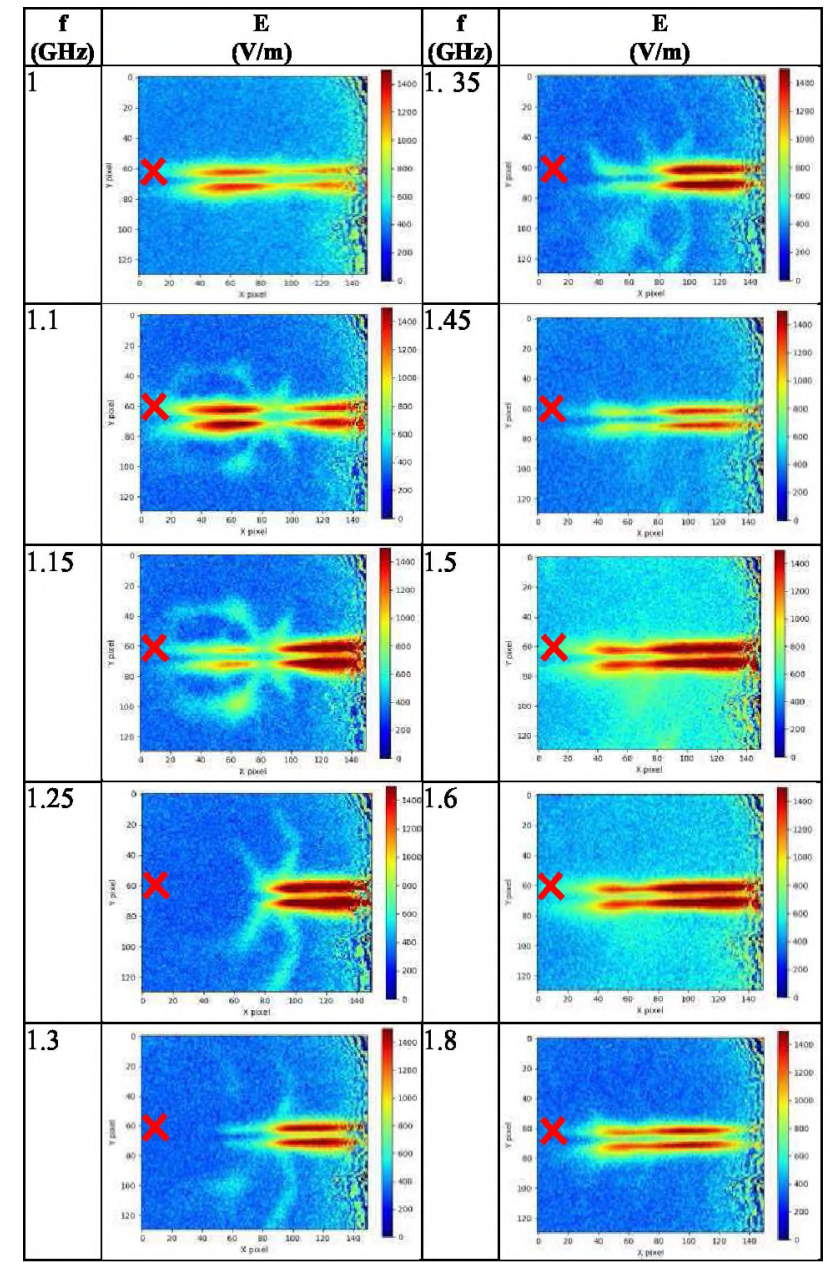

Figure 10 Electric field patterns at different frequencies

The Figure 10 exhibits different behaviors of the HIS depending on the frequency: at passing frequencies $(1 \mathrm{GHz}$ for example), the electric field appears along the line ; for a cut-off frequency (at $1.35 \mathrm{GHz}$ ), a resolution behavior arises and HIS cells resonate: subwavelength details of the electric near field are thus exhibited. We can note that visualizing these sub-wavelength details would have been impossible with a local probe.

Figure 11 shows the evolution of the amplitude of the field at the output side of the transmission line (corresponding to the red cross - $x=10, y=60$-, on the left of the Figure 10 . We obtain a good agreement with the $S_{12}$ measurement presented in Figure 9.

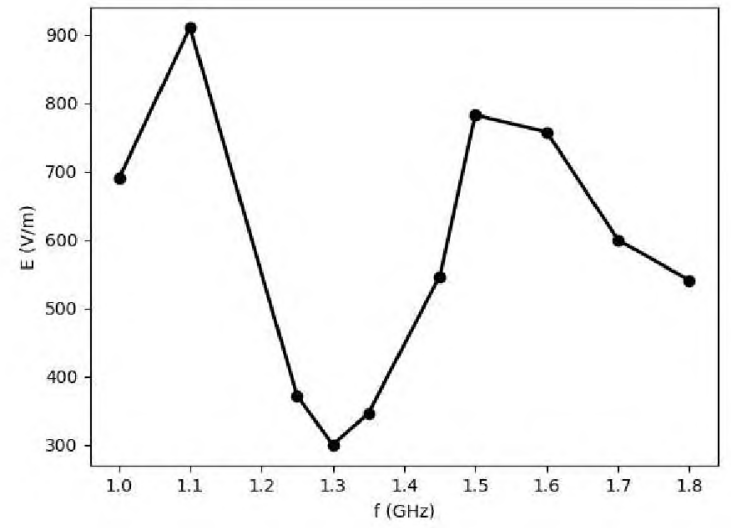

Figure 11 Output electric field on the HIS as a function of the frequency

\section{Images of magnetic field of HIS}

In this section, we present qualitative images of the magnetic field. Indeed, it was difficult to obtain a quantitative measurement because of the uncertainty of the ferromagnetic film properties (that are needed to evaluate the $k_{H}$ factor of the (7)). Images presented in Figure 12 although represent the square root of $\Delta T_{\text {mod, }}$ therefore proportional to the magnetic field (7). As previously, we observe a passing behavior at $1.1 \mathrm{GHz}$ and a resonant behavior at $1.3 \mathrm{GHz}$.

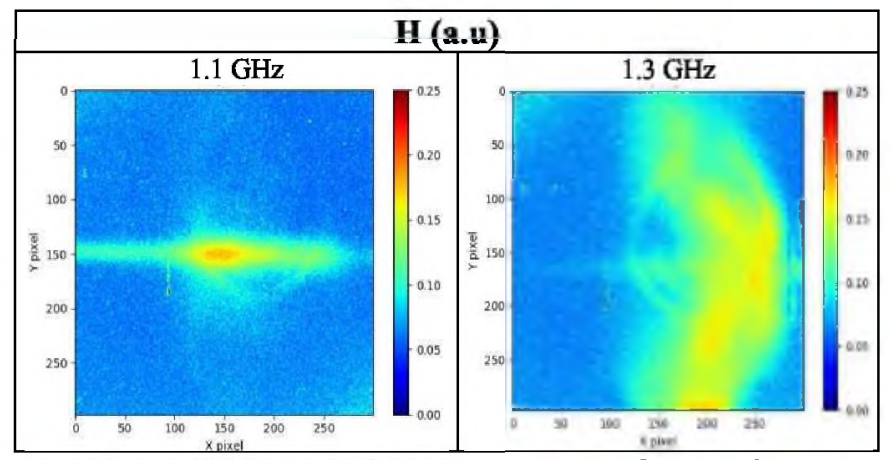

Figure 12 Magnetic field patterns at two frequencies

\section{CONCLUSION}

In this paper we presented characterization of two radiating systems using EMVI method. We exhibit complex near field pattern produced by ZOR antenna and HIS metamaterial structure. For ZOR antenna, electric and magnetic field patterns of the whole structure have been obtained for one frequency and one microwave power. For the HIS structure, electric field patterns have been obtained for a frequency range from $1 \mathrm{GHz}$ to $1.8 \mathrm{GHz}$ (first bandgap regions) and the magnetic field have been obtained for two frequencies (one in bandwidth and one in bandgap regions).

For ZOR antenna, the patterns show the behavior of the capacitor and inductor periodic elements. For HIS structure the electric patterns show how this structure behaves in the frequency range, more especially in the first bandgap regions. Image of magnetic field of HIS show the resonance of the HIS cells at $1.3 \mathrm{GHz}$.

We thus show that we can visualize complex near field by thermos-fluorescence. These kinds of field images are 
difficult to obtain by experimental usual methods (EM probes) or even by simulation. In the future we shall be able to distinct the components of the field, using anisotropic films.

\section{REFERENCES}

[1] P. Levesque, L. Leylekian, "Capteur vectoriel de champs électromgnétique par thermographie infrarouge ", French Patent n9816079, 1998

[2] S. Faure, J.F. Bobo, J. Carrey, F. Issac and D. Prost, "Composant sensible pour dispositif de mesure de champ électromagnétique par thermofluorescence, procédés de mesure et de fabrication correspondants", French Patent, $n^{\circ} 1758907,2017$

[3] H.I. Bassen, G.S. Smith, "Electric Field Probes", IEEE transactions on antenna and propagation, VOL.AP-31, NO.5, September 1983

[4] J. Lenz, A.S. Edelstein,"Magnetic sensors and their applications", IEEE Sensors Journal, VOL. 6, NO. 3, June 2006

[5] T. Hasegawa, "A new method of observing electromagnetic fields at high frequencies by use of test paper", Bull. Yamagata Univ. IV, Japan, 1995

[6] S. Faure, J-F. Bobo, D. Prost, F. Issac, and J. Carrey, "Electromagnetic Field Intensity Imaging by Thermofluorescence in the Visible Range", Phys. Rev. Applied 11, 054084, 2019.

[7] D. Prost, F. Issac, F. lemaître and J.P. Parmentier, "Infrared Thermography of Microwave Electromagnetic Fields", International Symposium on electromagnetic compatibility (EMC EUROPE), 2012

[8] https://www.tokin.com/english/product/pdf_dl/flex.pdf
[9] J. Carrey, B. Mehdaoui, and M. Respaud," Simple models for dynamic hysteresis loop calculations of magnetic single-domain nanoparticles: application to magnetic hyperthermia optimization', J. Appl. Phys. 109, 083921, 2011

[10] J. Lou, T.M. Finegan, P. Mahsen, T.A. Hatton and P.E. Laibinis, "Fluorescence-based thermometry: principles and applications", Dep of chemical engineering, Massachusetts Institute of Technology, Cambridge, MA 02139, USA

[11] S. Huth, O. Breitenstein, A. huber and U. Lambert, "Localization of gate oxide integrity defects in silicon metal-oxide-semiconductor structures with lock-in IR thermography",J. Appl. Phys. 88,4000, 2000

[12] G. breglio, A. Irace, L. Maresca, M. Riccio, G. Romano and P. Spirito,"Infrared thermography applied to power electron devices investigation", Facta Universitatis, Series: Electronics and energetics $28,205,2015$

[13] H. Ragazzo, S. Faure, J. Carrey, F. Issac, D. prost and J.F. Bobo, "Detection and imaging of magnetic field in the microwave regime with a combination of magnetic losses material and thermofluorescence molecules", IEEE Transmagn. 55, 6500104, 2019

[14] T. Crépin, F. Issac, D. Prost, and S. Bolioli, "Microwave electric field imaging of metamaterials using thermoemissive films", IEEE Antennas Propag. Mag. 56, 37, 2014

[15] D. Prost, F. Issac, C. Martel, N. Capet, J. Sokoloff, and O. Pascal," Electric firld imaging of a high impedance surface for GNSS array decoupling application", J. Appl. Phys, 72:11001, 2015

[16] N. Capet,"Amelioration du découplage inter élément par surface haute impédance pour antennes réseaux GNSS compactes",Ph.D. Report, Université de Toulouse, 3010, [in french] 